\title{
DESNATURALIZAR LO NATURAL. EL ALUVIÓN DE LA QUEBRADA DE MACUL COMO PROCESO SOCIAL EN SANTIAGO DE CHILE.
}

\author{
Denaturalize the Natural. The Landslide of 1993 in Quebrada de Macul as a \\ Social Process in Santiago de Chile.
}

\section{CONSUELO BISKUPOVIC*}

Fecha de recepción: 4 de enero de 2017 - Fecha de aprobación: 17 de mayo de 2017

\section{Resumen}

Las formas en que las personas explican los desastres "naturales", el rol que juega la ciencia, los expertos y el saber "técnico", permiten dar cuenta de cómo el aluvión de 1993 no se puede entender solamente desde la naturaleza. En un primer momento, este artículo revisa procesos y decisiones que permiten entender los efectos del aluvión de 1993 en la Quebrada de Macul, comuna de La Florida, Santiago, Chile. A través de los relatos de diferentes actores afectados por el desastre y la revisión de archivos guardados por protagonistas de la catástrofe, vemos cómo estos perciben y describen el aluvión. Las voces de los vecinos, habitantes de la precordillera, autoridades y científicos muestran cómo los antecedentes existentes previo al desastre son importantes para comprender el proceso político, de compromiso, que desarrollan progresivamente los habitantes de la precordillera. La falta de consideración de las particularidades territoriales invisibiliza las especificidades y vulnerabilidades a las que pueden estar expuestos los habitantes.

Palabras clave: aluvión; desastres; naturaleza; medio ambiente

\begin{abstract}
The ways in which people explain "natural" disasters, the role played by science, experts and "technical" knowledge, give an account of how the 1993 flood cannot be understood from nature alone. At first, this article reviews processes and decisions to understand the effects of the 1993 aluvión in Quebrada de Macul, commune of La Florida, Santiago. Through the stories of different actors affected by the disaster and the revision of archives kept by protagonists of the catastrophe, we see how they perceive and describe the aluvión. The voices of the neighbors, inhabitants of the precordillera, authorities and scientists allow us to realize how the antecedents that give account of the context before the disaster are important to understand the political process of engagement that the inhabitants of the precordillera progressively develop. This recent past allows us to understand how people explain "natural" disasters, and how these are not only due to reasons attributed to nature, but also the disregard for territorial particularities invisibilizes the specificities and vulnerabilities to which inhabitants may be exposed.
\end{abstract}

Keywords: landslide, disasters, nature, environment

* Dra. en Antropología. Académica Escuela de Antropología, Universidad Academia de Humanismo Cristiano. Santiago de Chile. Correo-e: mbiskupovic@academia.cl 
"Suceden hechos inesperados, naturales, que también introducen ideas de cambio; los aluviones, terremotos, lo que venga, te produce un cambio de ideas (...)", entrevista con funcionario del Departamento de Desarrollo Urbano, SEREMI MINVU, Región Metropolitana, (1/9/2008).

\section{Introducción. De los conceptos globales a los conceptos plurales.}

Entrevistadora: $Y$ cuando se construyeron ahí esas viviendas sociales, hechas por el Estado ¿nunca se supo que esos eran terrenos inundables o que podían ser impactadas por un aluvión?

L. : No, o sea yo creo que sí se sabía, lo que pasa es que se sabía que estaba cerca y que estaba cerca, era parte de alguna área del cono de eyección, pero nadie había hecho una investigación pa atrás, esa era la población ¿La Higuera?, La Higuera se llamaba esa zona, la población La Higuera, la Nuevo Amanecer está un poquito más abajo, La Higuera es la que tuvo mayor problema [con el aluvión]. Y, como te digo, fueron trasladadas de ahí 1800 familias más o menos, entre todos, propietarios, los allegados, todos, y eso que no fue inundada toda, o sea quiero decir no se sacó toda, se sacó un tercio no más, los otros dos tercios siguen viviendo donde mismo (entrevista, 18/4/2008).

Entre los habitantes de la Quebrada de Maculo también conocido como el sector de Lo Cañas - L. describe diferentes prácticas que tenían previamente al aluvión para saber o "controlar" efectos producto de las inundaciones. "Siempre ha habido bajadas de agua. Nosotros albergábamos gente en la capilla y la posta, cada cierto tiempo iban a echarle una miradita a la quebrada (...) Había conciencia de la quebrada" (entrevista con trabajador de la posta rural, 4/12/2009). El problema vino cuando hubo que ubicar a nuevos habitantes que desconocían el funcionamiento de la quebrada. "Éramos como una familia, en la década del 60' llegamos acá, nos criamos acá, eran 120 familias, todos nos conocíamos, teníamos buenas actividades, buenos dirigentes, estábamos bien organizados" (entrevista con vecino de Santa Teresa, La Florida, 18/1/2010). Poco a poco empezaron a llegar más familias y los lechos de las quebradas se fueron habitando. Antes del aluvión, el Estado construyó viviendas sociales muy cerca de la quebrada en zonas que, luego, fueron las más impactadas por el desastre. El problema de las inundaciones se repetía "es un problema de años. Todos los años se nos inundaban. Tenía que hacerse un sistema, nunca se hizo nada, nunca se limpiaron (...)."

\begin{abstract}
El cerro lo conocemos al revés y al derecho. No había recursos para ir a la playa entonces íbamos al cerro con la familia, con los amigos, nos bañábamos, etc. (...) Después del aluvión se dejó de hacer eso, se empezó a construir, se perdió todo. Teníamos mucho contacto con la naturaleza. En invierno íbamos a buscar leña, la gente no tenía estufa, usábamos leña y bracero... La tecnología nos ha hecho ser más cómodos, se ha perdido esa cosa más humana (entrevista con trabajador de la posta rural, 4/12/2009).
\end{abstract}

Al hablar de precordillera, en las entrevistas surge inmediatamente la asociación con la Quebrada de Macul y particularmente con el aluvión de $1993^{2}$. Ese año bajaron avalanchas de barro por la quebrada provocando lo que se conoció popularmente como el aluvión de la Quebrada de Macul, una de las peores catástrofes conocidas en Chile desde la década de 1950, según la $\mathrm{ONEMl}^{3}$. Desde entonces, ¿cómo los habitantes tejen lazos con una naturaleza frágil y "peligrosa"?

La precordillera está conformada por entidades contradictorias: zona de riesgo, hábitat de humanos y no-humanos, también es objeto de estudios científicos, geológicos, físicos. Es a su vez una naturaleza defendida 
por una agrupación de vecinos y habitantes de la comuna (Biskupovic, 2015), al mismo tiempo que es un "zona de protección", por ejemplo, gracias a la creación de un parque (Parque Quebrada de Macul) en el lugar donde ocurrió el aluvión de 1993. La precordillera está compuesta por una amplia variedad de actores y entidades que la constituyen, por la flora nativa, los vecinos que la protegen, los eventos como los aluviones, los científicos, los funcionarios municipales, entre otros.

Cuando las personas se refieren a la naturaleza, y en particular en las interacciones entre la sociedad y el medio ambiente, participan procesos y entramados híbridos (Callon, Lascoumes \& Barthe, 2001; Callon, 2004; Lolive, 2006; Blok \& Jensen, 2011). Sin embargo, la "protección" del medio ambiente, en particular en el ámbito legal, es habitualmente aprehendida desde categorías de orden universal (Gramaglia, 2006). La naturaleza aparece, así, como una entidad abstracta, desterritorializada, no situada.

Lo interesante, sin embargo, en el caso que presentamos aquí, es que aun en un contexto en el que las definiciones de naturaleza son divergentes, pues nacen de maneras distintas de vivir, de experiencias heterogéneas y de desigualdades sociales, los vecinos de la precordillera logran crear una demanda común 4 . Para hacer valer las particularidades de la naturaleza que defienden se basan en artículos científicos, en archivos de prensa, en conversaciones con expertos y vecinos (Biskupovic \& Canteros, 2019).

Los ejemplos en que el medio ambiente - la naturaleza son abordados a partir de las amenazas, crisis, destrucción, o para hablar de la sobrevivencia de la especie humana o del planeta, son cada vez más recurrentes en las ciencias sociales. $Y$ esto no debiera sorprendernos en esta época en que las sociedades están confrontadas al problema del clima mundial (Urry, 2015). Considerando la crisis ecológica actual (cambio climático, incendios monumentales, crisis hídrica, desplazamientos forzados, emergencia ambiental), el campo disciplinar chileno no ha sido excepción en abordar el medio ambiente desde el espectro de estos riesgos (Arnold \& Urquiza, 2010; Arnold, 2003; Robles, 2005, 2000).

En términos generales, en el marco de la crisis ambiental, el medio ambiente designa ya sea una totalidad muy vasta, o bien, una realidad no especificada. Este proceso de totalización del medio ambiente (Charvolin, 1997) se ve reflejado en cómo la ley chilena sobre Bases generales del Medio Ambiente lo designa:

\footnotetext{
Medio Ambiente: el sistema global constituido por elementos naturales y artificiales de naturaleza física, química o biológica, socioculturales y sus interacciones, en permanente modificación por la acción humana o natural y que rige y condiciona la existencia y desarrollo de la vida en sus múltiples manifestacioness (Ley №19300, 1994, p. 2).
}

La naturaleza no es definida ni considerada a partir de características propias. ¿Dónde empieza y termina el medio ambiente? ¿Una quebrada, un bosque, un cerro son parte o son el medio ambiente? El medio ambiente remite a una totalidad abstracta que engloba la cultura, los valores estéticos, sociales, etc. Estenssoro señala que el "Medio Ambiente" remite a una definición global, amplia, es decir, a un "amplio conjunto de sistemas naturales, socioculturales, sociales, económicos, culturales y estéticos" (Estenssoro, 2007, p. 93). 
Concordamos que medio ambiente excede la lógica del concepto de "recurso" y de la definición occidental predominante (Bonelli, 2017). Por ello, en este artículo desarrollamos un análisis para dar cuenta de las diferencias de escala que existen cuando hablamos de medio ambiente. De esta diferenciación o "variación de escalas de observación", como señala Jacques Revel, "se puede esperar un beneficio analítico en el acercamiento hacia los fenómenos (...) un enriquecimiento de las hipótesis y de las interpretaciones que somos capaces de formular" (Revel, 2011, p. 25). El ejercicio de dar cuenta de distintas escalas de análisis permitiría mostrar "una pluralidad de mundos sociales" sobre el medio ambiente.

En Chile, pocos trabajos etnográficos se han centrado en la experiencia cotidiana de las movilizaciones sociales en lo que respecta al medio ambiente (Biskupovic, 2015), en las relaciones cotidianas con el medio ambiente, en la experiencia sensible de la democracia, (Blondiaux \& Traïni, 2018) o, en cómo ciertos eventos o preocupaciones pueden transformarse en problemas públicos (Cefaï, 1996; Céfaï, Terzi, \& Collectif, 2012).

Por otra parte, basándonos en el trabajo de campo sobre controversias ambientales en Chile, es posible señalar que las personas no tienen una comprensión totalizante del medio ambiente, tampoco abstracta y difícilmente homogénea, sino que las definiciones y comprensiones están dadas por sus experiencias cotidianas. En el contexto del compromiso ciudadano y de las interacciones hombre-naturaleza observadas los últimos años, no existe un "Medio Ambiente", con mayúsculas y en singular (Estenssoro, 2007). Tal como lo expresa Veyne, a propósito de la historia, "la Historia con mayúscula no existe: no existen sino 'historias de'” (Veyne, 1996, p. 29), lo mismo sucede con el medio ambiente o la(s) naturaleza(s).

Como propone Ingold (2000), más que dividir, separar y construir categorías aisladas, es necesario integrar y combinar en el análisis lo que sienten, lo que viven, lo que han vivido, lo que esperan vivir las personas. Igualmente, resulta necesario indagar en lo que saben y lo que es (Bonelli, 2017) lo que comúnmente llamamos medio ambiente. Datos científicos, experticia, observaciones, constataciones... más que separar los cuerpos (lo que sienten, perciben, manifiestan) y los espíritus (lo que piensan), estudiando la relación entre sujetos y naturaleza, podemos considerar simultáneamente las diferentes experiencias que los actores comunican.

La naturaleza no puede ser reducida a una definición. Retomando la idea ampliamente difundida por Latour de ensamblajes podemos señalar que "la naturaleza ya no es lo que se abarca desde un punto de vista distante al que el observador puede saltar idealmente para ver las cosas 'como un todo', sino el ensamblaje de entidades contradictorias que deben ser compuestas como un conjunto" (Latour, 2012, p. 71).

Así como la ciudad no es una entidad estática (Jirón, 2009), la naturaleza o el medio ambiente tampoco pueden ser considerados como algo inmutable, ni como un conjunto que englobaría un todo abstracto. Es importante integrar las dimensiones distintas o contrastantes (Ingold, 2000; Ingold \& Palsson, 2013). 
En este artículo veremos cómo se produce un desastre que no es solo "natural" sino que está imbricado de acciones humanas. A partir de un análisis de diferentes tipos de documentos (informes, estudios, prensa) reconstruimos cómo se produce el aluvión de 1993 en la Quebrada de Macul y lo que produce posteriormente este desastre. La consideración de las competencias específicas desplegadas por los especialistas habría podido evitar la catástrofe, pero las políticas territoriales, al no considerar las especificidades y particularidades del piedemonte, ponen en riesgo a una población ya vulnerable socialmente que ahora es vulnerable también en relación con los peligros que existen en la precordillera.

Así mismo, analizamos qué representan los peligros para los distintos actores implicados en la catástrofe y cómo los comportamientos de la naturaleza tienen explicaciones y contenidos tanto esperados como inesperados. Mientras que para algunos actores, como los funcionarios entrevistados, las responsabilidades son compartidas, otros deben buscar diferentes tipos de explicaciones que les permitan justificar donde viven, expuestos a peligros "naturales".
El foco es mostrar cómo las decisiones humanas producen cambios en el medio ambiente que afectan a las personas y cómo las personas explican estas transformaciones. El saber científico juega un rol importante para los ciudadanos en la medida que les permite entender las amenazas antrópicas, aprehender y entender donde viven, aun cuando la precordillera también tiene comportamientos inesperados.

La idea de desnaturalizar la naturaleza se refiere al hecho de no tomar por dado lo que significa "naturaleza", es decir, des familiarizarse de la naturaleza, no considerarla como algo evidente, estable, que está ahí como telón de fondo en nuestras acciones, sino que, al contrario, intentar comprender lo que evoca en cada contexto.

Tal como señala Descola, si humanos (científicos, ciudadanos, políticos) se preocupan constantemente de calificar la naturaleza, es posiblemente "porque estas personas tienen una relación muy particular con la naturaleza" (Descola \& Tola, 2018, p. 20). 
Foto 1: Parque Quebrada de Macul, lugar por donde bajó el aluvión de 1993. La reja funciona como división entre la quebrada y el parque.

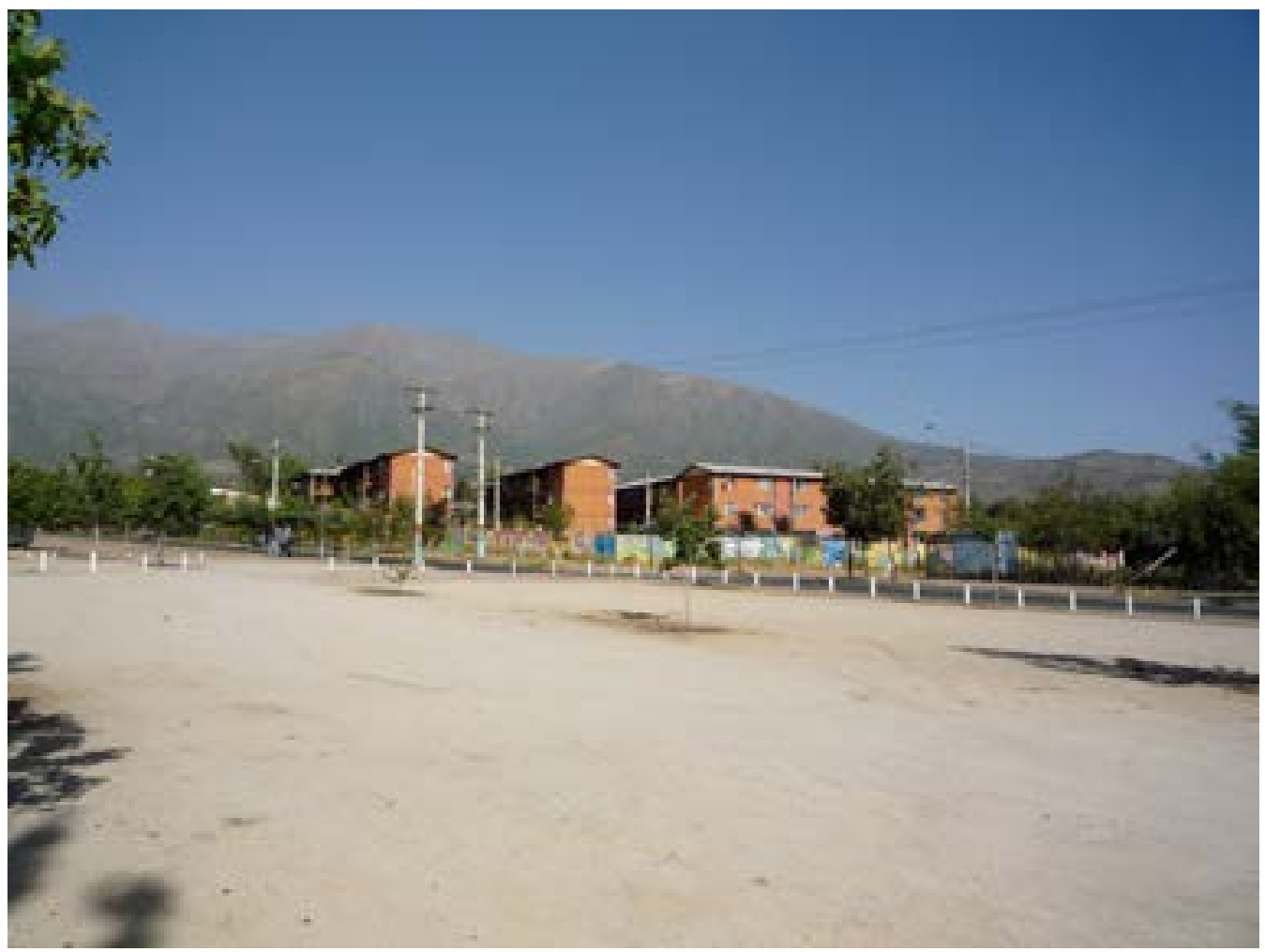

Foto de la autora.

\section{El rol humano en la vulnerabilidad de los territorios y habitantes frente a las catástrofes "naturales".}

En el otoño de 1993 avalanchas de barro destruyeron cientos de casas e invadieron diversos barrios de Santiago. Fue uno de los aluviones más importante que ha tenido lugar en la capital, afectando cinco comunas y dejando a su paso alrededor de treinta mil personas damnificadas (Secretaría Regional Ministerial de Salud, 1999). Ese 3 de mayo en la mañana, un primer mar de barro descendió por la Quebrada de Macul, en la comuna de La Florida. Una geóloga describe la primera ola como de más de un metro de alto y de casi 300 metros de ancho que se desplazaba a una velocidad de casi $15 \mathrm{~km} / \mathrm{h}$ (Padilla, 2006). Esta ola traía bloques de rocas de más de un metro de diámetro, troncos de árboles y barro viscoso. Diez minutos más tarde, a las 11:50, casi como una réplica a la primera ola de este "tsunami de barro", un segundo flujo descendía por la quebrada que sobrepasaba los 3 metros de alto y avanzaba a casi $30 \mathrm{~km} / \mathrm{h}$ (Padilla, 2006).

Debido a las precipitaciones intensas de ese día y a la lluvia en zonas altas de la cordillera donde generalmente nieva, en otras quebradas algunos aluviones eran de unos 6 metros de alto (Naranjo \& Varela, 1996; Martínez, 2009). 
Según Padilla (2006), desde al menos hace 25 años que eventos de similares características se registran en esta zona, salvo que precedentes de uno tan grave como el de 1993 no habían. En los bordes de la Quebrada de Macul se habían establecido cuatro poblaciones: El Esfuerzo, Fernando Domínguez, El Progreso y La Higuera. Las cuatro fueron afectadas por los ríos de barro, pero en particular una de ellas, El Progreso, quedó completamente destruida. Las 357 familias pobres que vivían en estos barrios fueron las afectadas por el aluvión y, si bien los datos de la época no son precisos y difieren según las fuentes, el número de muertos rondó los treinta. Seis días después del aluvión, el diario El Mercurio hablaba de once muertos y de 1.800 siniestrados, de 4.000 personas afectadas por la "catástrofe" y de 200 viviendas destruidas (El Mercurio, 1993a). Otro medio, hablaba de 356 familias que "perdieron todo" (La Nación, 1993). En 2009, El Mercurio publica un reportaje sobre los "16 peores desastres" entre los cuales el aluvión de Macul se sitúa quinto. Aquí se habla de 26 muertos, ocho desaparecidos, de un total de 32.654 siniestrados y de 307 viviendas destruidas (EI Mercurio, 2009).

Antecedentes para haber previsto este "desastre" existían. María Beltrán, por ejemplo, urbanista y arquitecta de la Universidad de Chile, llevó a cabo una investigación - financiada por el Estado - donde según sus palabras predecía la catástrofe, en particular en la Quebrada de Macul (El Mercurio, 1993c). Además, tres importantes aluviones habían sido registrados en 1982, 1986 y 1987 por distintos geógrafos, entre los que estaba Jorge Villagrán, quien había detectado zonas peligrosas para instalar viviendas sociales (El Mercurio, 2009).
Al mirar con más detalle los documentos de diversas autoridades de la época, estas intentaron sobre todo dar una respuesta a la población afectada durante y después de la catástrofe. Los problemas son abordados sin considerar la historia del lugar, tampoco la geografía, ni la presencia de quebradas. La Secretaría Regional Ministerial de la Salud de la Región Metropolitana, por ejemplo, publica en 1999 un documento sobre los principales desastres entre 1990 y 1999 donde señala la importancia de poder reaccionar "multi-institucionalmente" frente a urgencias (Secretaría Regional Ministerial de Salud, 1999). Las evaluaciones de la catástrofe se centran en la inmediatez, sobre lo que debió hacerse durante y después y sobre lo que no se hizo bien o no se organizó bien.

Por azar, accedí a algunos documentos de la Municipalidad de La Florida entre el 2008 y 2010 , gracias a que un funcionario de la oficina de desarrollo urbano había guardado una gran cantidad de archivos de la época, recortes de diario, entre otros documentos. Al descubrir un armario lleno de archivos, le pregunté si podía revisarlos. Me ofrecí a ordenarlos, fotocopiarlos y leerlos, a lo que accedió.

Igualmente, gracias a la Ley de Transparencia, en el 2014 accedí a información sobre la legalización, división y construcción de las poblaciones (El Progreso, Domínguez, El Esfuerzo $)^{5}$. En estos se confirma la aprobación por parte del Estado de la construcción de las poblaciones El Progreso y El Esfuerzo (en 1984 y 1987, respectivamente), las que también fueron afectadas por el aluvión del 1993.

En un informe relativo a la aprobación de la legalización del barrio El Esfuerzo, un extracto particularmente interesante describe 
como el Departamento de Urbanismo de la Municipalidad de La Florida solicita la autorización del alcalde para nombrar un arquitecto de la misma Municipalidad para que firme el plan de construcción de la Villa El Progreso (ejecutada por la municipalidad) ${ }^{6}$. Esto, para asegurar asistencia técnica pues se trata de "pobladores de escasos recursos" (informe de la Municipalidad de La Florida del 13 de julio, decreto 589, anexo 4). Algunos días más tarde, en otro informe municipal (del 24 de julio 1984), la Municipalidad de La Florida anuncia que la construcción de El Progreso es aprobada según las disposiciones del Plan de Urbanismo en vigor y de la ordenanza local. Por consiguiente, los archivos muestran la aprobación por parte de la Municipalidad y del SERVIU respecto a las construcciones que se levantaron en los años 1980 en la precordillera. Los argumentos para tales aprobaciones son únicamente técnicos y difícilmente interpretables sin un conocimiento profundo del sistema legal (por ejemplo, "el artículo 10, parágrafo b) párrafo $1^{\circ}$ del D.S. (V.y U.) - № 458 del 13.04.76"). Sin embargo, se constata la ausencia de mención a las condiciones morfológicas del territorio y aún menos a los riesgos a los cuales se exponían estas nuevas construcciones. Cuando el representante técnico (el arquitecto de la Municipalidad en este caso) aprueba el proyecto de construcción, esta obedece a criterios legales ligados al Plan regulador que se aplican en toda la ciudad, sin consideración particular del territorio, de las quebradas y de los aluviones e independientemente de los peligros latentes.

La historia de estos terrenos está marcada por procesos de ocupación ilegal seguidos de expulsiones y reinstalaciones (Muñoz, 1990). Estos procesos de ocupación y hábitat informal en el país - debido a movilidades familiares, vulnerabilidad social, precariedad, entre otros - son parte de una transformación natural a través de las cuales las ciudades chilenas se han construido (Pino \& Ojeda, 2013).

En 1955, los terrenos cercanos a la Quebrada de Macul eran principalmente cultivos que poco a poco comienzan a ser parcelados (Muñoz, 1990). Podemos ver que es a partir de estos años que la precordillera comienza a poblarse, con construcciones precarias y en terrenos frágiles, bajo un escaso o nulo control de las autoridades. Un poco antes, en 1950, comienzan las subdivisiones de lo que será posteriormente La Higuera, barrio que desaparece en gran medida por el aluvión de 1993. El objetivo de estas subdivisiones es crear pequeñas parcelas agrícolas. Sin embargo, hacia 1960 , el sector conoce una progresiva densificación. Es en este periodo que, luego de tomas u ocupaciones ilegales e informales, comienzan a desarrollarse las poblaciones del Esfuerzo y Domínguez.

Según Muñoz, en la década de 1970 los habitantes de la población Domínguez - que para ese entonces recién se había terminado de construir - extienden sus construcciones y terrenos hasta el lecho de la quebrada (Muñoz, 1990). Fundada por ocupaciones ilegales también, el Progreso se erige en 1971 y su aprobación por la Municipalidad no ocurre sino trece años después. El crecimiento del sector, como ocurre en otras partes del país (Pino \& Ojeda, 2013), es caótico y espontáneo, las viviendas son construidas por sus propios habitantes, sin asistencia técnica ni menos planificación. Considerando que al mismo tiempo se trata de habitantes "nuevos" que llegan a residir aquí, tal como señala 
José7, estos tampoco tenían el conocimiento y la experiencia previa de lo que significa vivir cerca de una quebrada.

En los años 90', previamente al aluvión, estas poblaciones ya habían sido afectadas por varios episodios de crecidas e inundaciones (Muñoz, 1990). Además de las crecidas en los lechos de las quebradas, las precarias construcciones soportan mal los comportamientos del piedemonte andino.

Foto 2: Animita en la Quebrada de Macul para recordar las víctimas del aluvión de 1993.

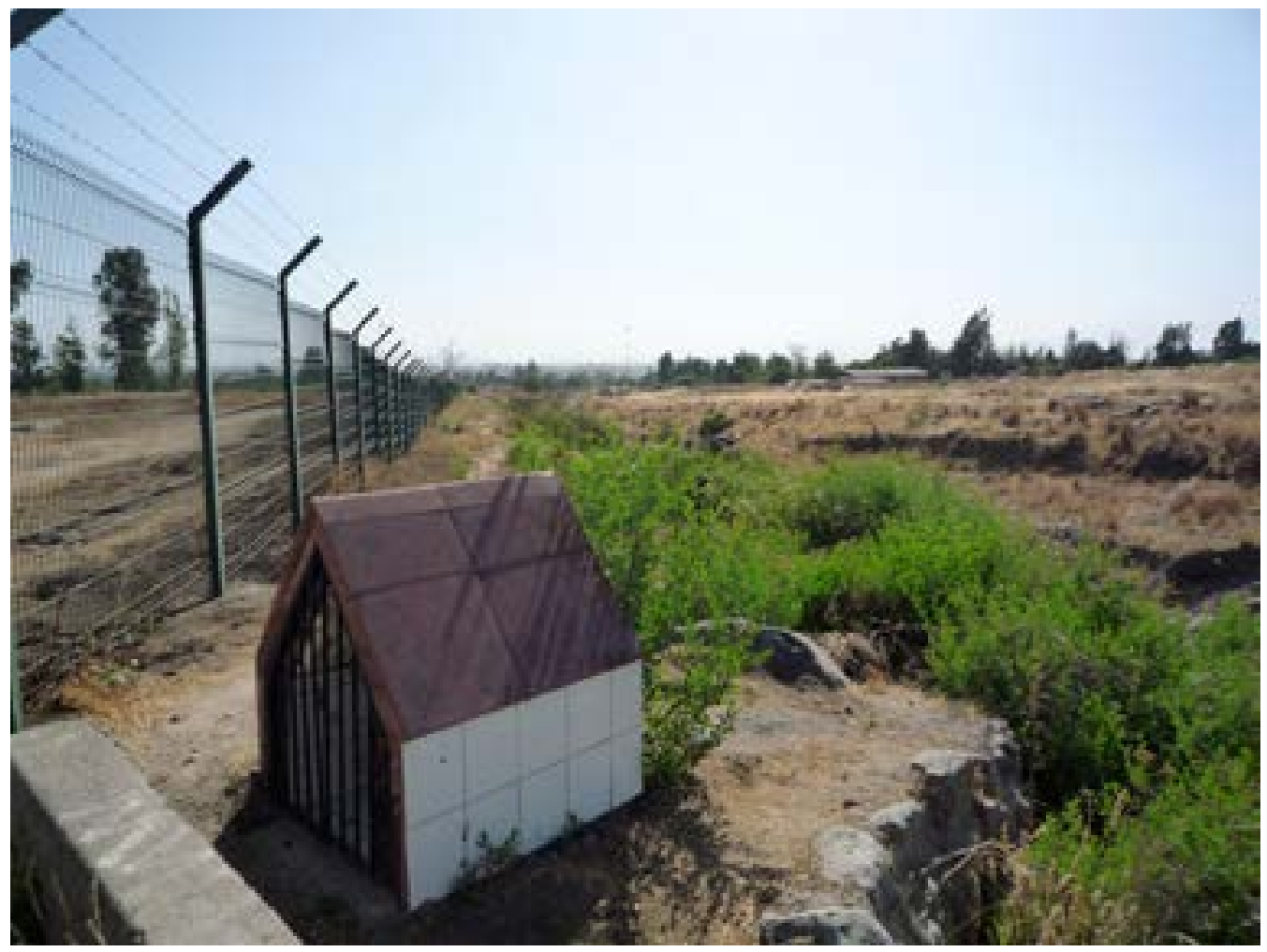

Foto de la autora.

José me explica que la consolidación de las poblaciones El Progreso y Domínguez data de los años 1950. Cuenta que en 1970 nuevas poblaciones surgen y que, aun cuando al principio los recién llegados se instalan ilegal y precariamente, poco a poco el Estado legaliza estas ocupaciones permitiendo a los habitantes volverse propietarios ${ }^{8}$. En efecto, las primeras instalaciones a algunos metros de la Quebrada de Macul son tomas conformadas por pequeños agricultores de clases populares. 
Estela ${ }^{9}$, habitante de las parcelas cercanas a la Quebrada, pero de un barrio más acomodado conocido como Santa Sofía de Lo Cañas, me presenta un panorama un poco distinto. Señala que aquí también vivían trabajadores de profesiones liberales, tal como su cuñada, o "una alemana", me dice, "que se ganaba la vida como traductora (...) Todo el mundo se imagina que eran poblaciones callampa ${ }^{10} \mathrm{y}$ no eran, eran poblaciones SERVIU, casas de ladrillo..." (Entrevista con Estela, 31/07/2008). Validadas por el Estado, estas poblaciones conformaban "la única parte más urbanizada de este sector, tenían calles pavimentadas, tenían postes, tenían teléfonos públicos, o sea era como un sector urbanizado, un pedazo de ciudad dentro de esto que no lo era." (Entrevista con Estela, 31/07/2008).

Es importante señalar que las tomas, en particular la población Domínguez, son legitimadas cuando el Estado compra estos terrenos en los años 1960, hasta entonces agrícolas. En respuesta a las necesidades siempre crecientes de viviendas sociales, la Municipalidad busca dar respuesta a esta demanda. El Estado no solo legaliza estas ocupaciones, sino que además diversos servicios públicos urbanizan poco a poco estos barrios, normalizando la ocupación de la precordillera y por tanto aumentando el riesgo de posibles catástrofes. Una vez que los habitantes llegan a vivir aquí, los "pobladores de pocos recursos" no están suficientemente informados sobre los peligros de vivir cerca de quebradas. Como veremos a continuación, desde la Municipalidad se espera que sean los habitantes quienes deban informarse sobre los peligros.

\section{3. "La falta es compartida": la responsabi- lidad frente a la catástrofe.}

Para L., la "falta es compartida": por una parte, el Estado es responsable frente al desastre pues construyó viviendas en una zona peligrosa, pero al mismo tiempo también los vecinos tienen responsabilidad, pues debieron "informarse más" al momento de instalarse en la precordillera:

\footnotetext{
Claro, son tomas, tomas, pero lo más divertido es que después el mismo Estado en muchos casos, incluido la Municipalidad..., es culpa compartida, les dio casa igual, o sea, en una de estas zonas construyó viviendas el Estado (...) Entonces ahí nosotros nos dimos cuenta que había gente que vivía efectivamente dentro de los conos de eyección, si ellos no tendrían por qué haber estado nunca ahí, ¿te fijas? pero la gente siempre lo tenía, lo tenía en la memoria inconsciente que efectivamente estaban en zonas que no debieran estar ocupadas. (Entrevista con L., 18/4/2008).
}

Para L., los habitantes no son víctimas, se trata más bien de una responsabilidad compartida porque son responsables de la elección del lugar donde viven. La idea de una "memoria inconsciente" puede referirse al hecho que los habitantes sabían de algún modo el peligro que corrían, pero al tratarse de habitantes desfavorecidos, estos no tienen otras opciones residenciales. El desarrollo de tomas en quebradas obedece a una multiplicidad de causas y factores sociales relacionados con vulnerabilidad social y medioambiental (exposición a los peligros de la quebrada). Los lechos de las quebradas eran terrenos desocupados, fácilmente "tomables" y que por otro lado presentan características favorables al desarrollo de una pequeña agricultura, tal como los habitantes cercanos resaltan en sus relatos. 
Por otro lado, el peligro difícilmente puede volverse legítimo y comprendido para los habitantes si el mismo Estado y la Municipalidad, tal como lo expresa el funcionario, validan estas ocupaciones y desarrollan proyectos de viviendas sociales en los peligrosos lechos.

Si bien el funcionario señala que los habitantes "tenían en la memoria" el peligro, muchos de estos habitantes eran recién llegados, por ende, desconocían las amenazas de las quebradas.

Llama la atención que L. asuma que el Estado y la municipalidad les dio casa "igual", es decir que, aun cuando sabían de los peligros, "igual" construyeron viviendas sociales. L. evita formular acusaciones y reconoce que concretamente la información existía, pero que no sirvió de base para la acción del Estado. Cuando le pregunto si el Estado sabía que estos terrenos, donde se construirían viviendas sociales, eran inundables y vulnerables, responde: "No, o sea yo creo que sí se sabía, lo que pasa es que se sabía que estaba cerca [de la quebrada], (...) pero nadie había hecho una investigación pa' atrás" (entrevista 18/4/2008).

Sin embargo, revisando los archivos anteriormente mencionados, observamos que las investigaciones sí existían. Cabe señalar que las leyes de la planificación urbana son bastante limitadas en Chile, no hay una autoridad de planificación centralizada (Lorenz, 2014). Además, el régimen militar estableció un sistema político jerárquico en el cual la toma de decisiones está fuertemente centralizada (Oxhorn, 1992). A esto se agrega el hecho que muchas veces las autoridades a nivel municipal tienen competencias bastante ambiguas (Dockendorff, et al., 2000).
En 1990, 5.594 personas en total viven cerca de la quebrada de Macul y entre 500 y 1.000 son periódicamente afectadas por las crecidas de la quebrada. Según este autor, la población se ve afectada debido a la incertidumbre frente a la recurrencia de estos episodios. En 1982 y 1986 se registran crecidas que inundan las poblaciones aledañas, pero estas tienen poca atención por parte de las autoridades municipales para quienes aún se trata de "situaciones inesperadas" (Muñoz, 1990, p. 122). El "riesgo latente" y la creencia, errónea, de que se trata de una zona de seguridad se deben a la falta de conocimiento del medio natural, lo que se solucionaría con un conocimiento apropiado y decisiones políticas que orienten las actividades humanas (Muñoz, 1990). La precordillera es gobernada como cualquier otro territorio, sin considerar sus particularidades, ni todas las entidades contradictorias que participan en y del territorio.

Las intervenciones humanas, materiales, son concebidas según los niveles "normales", considerando un medio natural estable e inmutable. Esto sin duda acelera los "desbordes" (Corvalan, et al., 1997, p. 143). Por ejemplo, en 1983, la municipalidad construye diques, pero estos no soportan las crecidas de la época (Corvalan, et al., 1997). Por otra parte, los servicios públicos se confunden y no logran determinar quién debe ocuparse frente a estos "eventos" recurrentes en que la naturaleza deja de comportarse "como siempre" o regularmente. En un informe preparado por un geógrafo para la municipalidad de La Florida sobre los cursos de agua e inundaciones en la comuna, el autor señala la ausencia de comunicación entre las diversas instituciones para establecer una política común. No hay contacto, señala, cada cual actúa independiente- 
mente y, agrega, la participación relativa al hábitat urbano es mediocre, casi nula (Garay, 1989). En este sentido, los conocimientos, los recursos y la capacidad de anticiparse de las autoridades son deficientes frente a eventuales desastres.

L. recalca que en 1984 los límites urbanos de la comuna se expandieron. Si antes de esto las parcelas eran más bien agrícolas y las crecidas e inundaciones afectaban a una escasa población, con la extensión de los límites urbanos los riesgos aumentan porque no hay regulación en términos de prevención de riesgo y también aumenta la población expuesta. Aunque existían antecedentes que fueron presentados por los expertos a las autoridades (Corvalan, et al., 1989), esto no fue suficiente para servir de base para informar a los habitantes o prevenir los riesgos. En 1990, Muñoz y sus colegas hacen un estudio y determinan zonas de alto riesgo, justamente las mismas donde en 1993 sucede el $90 \%$ de las muertes con el aluvión. Corvalan, et al., (1989) señalan que, si se trata de determinar culpables, no es posible dejar de considerar la ausencia de planificación respecto al crecimiento urbano, además de la nula consideración del medio natural.

Llama la atención como año tras año, mientras los expertos señalaban la importancia de considerar las particularidades y las condiciones específicas de la precordillera, el saber sobre el medio natural no fue tomado en cuenta a la hora de planificar los barrios más pobres: las poblaciones Fernando Domínguez, El Esfuerzo, El Progreso, La Higuera prácticamente desaparecen del mapa posteriormente al aluvión de 1993 (Corvalan, et al.,1997).

Luego del aluvión, los habitantes que "tenían animales, que plantaban tomates y que vivían de eso" (entrevista con Estela, 31/07/2008) se enfrentan a un nuevo entorno, no solo natural, sino que material.

Desde la década de 1940 que las personas que vivían aquí eran pequeños trabajadores agrícolas de Lo Cañas. A partir de 1970, señala L., para evitar futuras tomas de habitantes que no tenían casa, comienzan a desarrollarse proyectos habitacionales, "la gran explosión de las poblaciones" (entrevista con L., 18/04/2008) que se ve consolidada con la llegada de Salvador Allende. Posteriormente al desastre, el barrio se transforma drásticamente, tal como señala en esta entrevista otra habitante del barrio de parcelas de Santa Sofía de Lo Cañas:

A: (...) Ahí también el alcalde se fue al chancho...el antiguo alcalde. Estos eran terrenos que iban a ser para la gente que perdió su casa en el aluvión, en Las Perdices, que eran todos gente, jtodos campesinos también! Mucho campesino, mucho artesano, muchos talleres... la gente pensaba que le iban a entregar una parcelita. ¡Hicieron 1.200 departamentos!

Entrevistadora: ¿Los blocks rojos?

A: Sí, y de seguro que son atroz (sic). ¡Porque son de 25, $24 \mathrm{~m} 2$ las casas, $24 \mathrm{~m} 2$ ! 12 abajo y 12 en el segundo piso. $\mathrm{Y}$ ahí sí que trajeron de montones de barrios de Santiago (...) (Entrevista con Ana, 06/04/2008).

El barrio se reestructura a la luz de los cambios en las quebradas, en la precordillera. Las maneras de vivir y las relaciones de las personas con el entorno se modifican. Estela y Ana evocan con indignación las transformaciones que sufrieron los habitantes pobres post aluvión. Si bien antes se trataba de barrios precarios "sus situaciones eran bastante mejores que con las viviendas sociales" (Entrevista con Ana, 06/04/2008).

La situación de urgencia desencadena un proceso irreversible a partir del cual los vecinos 
se encuentran, se ayudan, se apoyan, se conocen, comparten una experiencia común y se identifican en relación con esta tragedia compartida. Sin embargo, una vez que pasa la urgencia, la nueva normalidad molesta a los habitantes en la medida que se desencadena un proceso irreversible de desarrollo inmobiliario en la precordillera. Contener, regular y gestionar la precordillera, posteriormente al aluvión, lleva al mismo tiempo a su ocupación. Las nuevas construcciones modifican las relaciones con el entorno. Estela, por ejemplo, habla de "esta cosa" para referirse a los nuevos blocks construidos para albergar a los ex habitantes de las viviendas afectadas por el aluvión.

A partir de los diferentes documentos revisados observamos que el aluvión aparece como un hecho impredecible, inesperado, como una "catástrofe natural". Pero lo que causa la catástrofe es el encuentro de un fenómeno natural y la vulnerabilidad de una sociedad (Revet, 2006). Las catástrofes desencadenan transformaciones, nuevas dinámicas y favorecen la emergencia de nuevos discursos como el de Estela y Ana.

La Oficina Nacional de Emergencia, ONEMI, distingue desastres provocados por fenómenos naturales, las "amenazas naturales" o de "origen natural", tal como los terremotos, inundaciones o aluviones, y los ocasionados por la acción del hombre, de "origen antrópico" tales como los incendios, los accidentes carreteros y la contaminación del aire (ONEMI, 1996). Siguiendo esta clasificación podemos observar que los impactos y el número de muertos son considerablemente mayores en el caso de las catástrofes ocasionadas por la acción del hombre. Las amenazas naturales aparecen como menos graves y, debido a la ocurrencia esporádica y a los altos costos de los trabajos de protección necesarios, las medidas para enfrentar estos fenómenos tales como los aluviones, no son una prioridad en el marco de las decisiones político-administrativas (Corvalan, et al., 1989). Explicar los aluviones en tanto que eventos imprevisibles implica, de alguna manera, responsabilizar a la naturaleza.

Como ya fue señalado, el poblamiento progresivo en las quebradas no considera los estudios de expertos sobre el comportamiento de la precordillera. Es entonces a partir de estos peligros que los vecinos van a crear un movimiento de compromiso político partiendo del principio que los peligros son desencadenados por actividades humanas (Douglas, 1966) y no se deben a la voluntad de la naturaleza. La naturaleza se vuelve motivo de investigación para los habitantes (Dewey, 2010a). Las autoridades piensan la naturaleza como una entidad exógena, que no está integrada a la ciudad. La ciudad está gobernada como un dato estadístico, enfrentada a situaciones imprevisibles tal como los peligros de "origen natural".

Los habitantes entrevistados están "asociados" (Latour, 2005) a la precordillera, es decir, reaccionan progresivamente a las transformaciones de su medio ambiente, tienen teorías frente a lo que viven, se informan, actúan. Mientras las autoridades tienen dificultades para actuar y pensar el conjunto de problemas que puede ocasionar catástrofes, científicos como Francisco Ferrando (geógrafo e investigador de la Universidad de Chile) perciben la precordillera como un actor, no humano, dotado de un rol preciso, le atribuyen particularidades que habría que tomar en cuenta en las decisiones públicas. Evoca la "rabia" con la que puede actuar la precordillera, explica la importancia de trazar el 
camino por donde esta pueda dar libre curso a su "naturaleza". Añade que "dada la experiencia y lamentablemente la memoria histórica de las personas y las autoridades es frágil" (entrevista Ferrando en la radio, $12 / 06 / 2008^{11}$ ), recomienda la construcción de nuevas infraestructuras: "un corredor que tenga las dimensiones que la quebrada en esos eventos requiere para desahogar su energía, para depositar su masa o para transitar sin generar daño al medio ambiente construido (...) de modo de tener lo que uno, se le llama normalmente, un camino por donde la naturaleza pueda desahogar su furia, entre comillas", (entrevista Ferrando en la radio, 12/06/2008) (El énfasis es nuestro).

Para Ferrando (2014), el peligro es latente si se consideran las características de la precordillera. Para los habitantes, los problemas no acaban con el término de la catástrofe. Los que vivieron el aluvión fijaron una alianza a partir de lo que vivieron, conformando progresivamente un movimiento político: "te das cuenta que tu casa la construiste mal, acá, al lado de la quebrada", (entrevista con Estela, 14/05/2008). Clasifican el espacio donde viven, comienzan a distinguirlo y definirlo, va adquiriendo nuevos significados.
La quebrada y otros elementos específicos de la precordillera no pueden considerarse como elementos fuera del sistema social. Por ende, estos deben ser analizados en el contexto de los procesos que contribuyen a su diferenciación y definición, es decir, en relación con las nociones de territorialidad y territorio (Di Méo, 1998). En este sentido, la precordillera es un espacio apropiado, colectivamente que, poco a poco, va siendo transformado en un recurso para el colectivo que se va a constituir posteriormente para defenderlo ${ }^{12}$.

"El piedemonte tiene un sentido, o sea, no tiene un sentido, sino que cumple una función dentro de la cuenca" (entrevista con Ana, 06/04/2008). Cada parte de este piedemonte cumple una función y tiene una razón de ser. La conformación de la organización política es el siguiente paso para configurar y desarrollar un conocimiento apropiado para relacionarse con los científicos, con las autoridades, con los vecinos (Di Méo, 1998). Lejos de irse a otro lugar, los habitantes se quedan a vivir en la precordillera, reafirmando su voluntad de defender este territorio. La catástrofe es un evento que transforma no solo a los afectados, sino que también las relaciones con el lugar. 
Foto 3: viviendas sociales construidas posteriormente al aluvión de 1993 frente al Parque Quebrada de Macul.

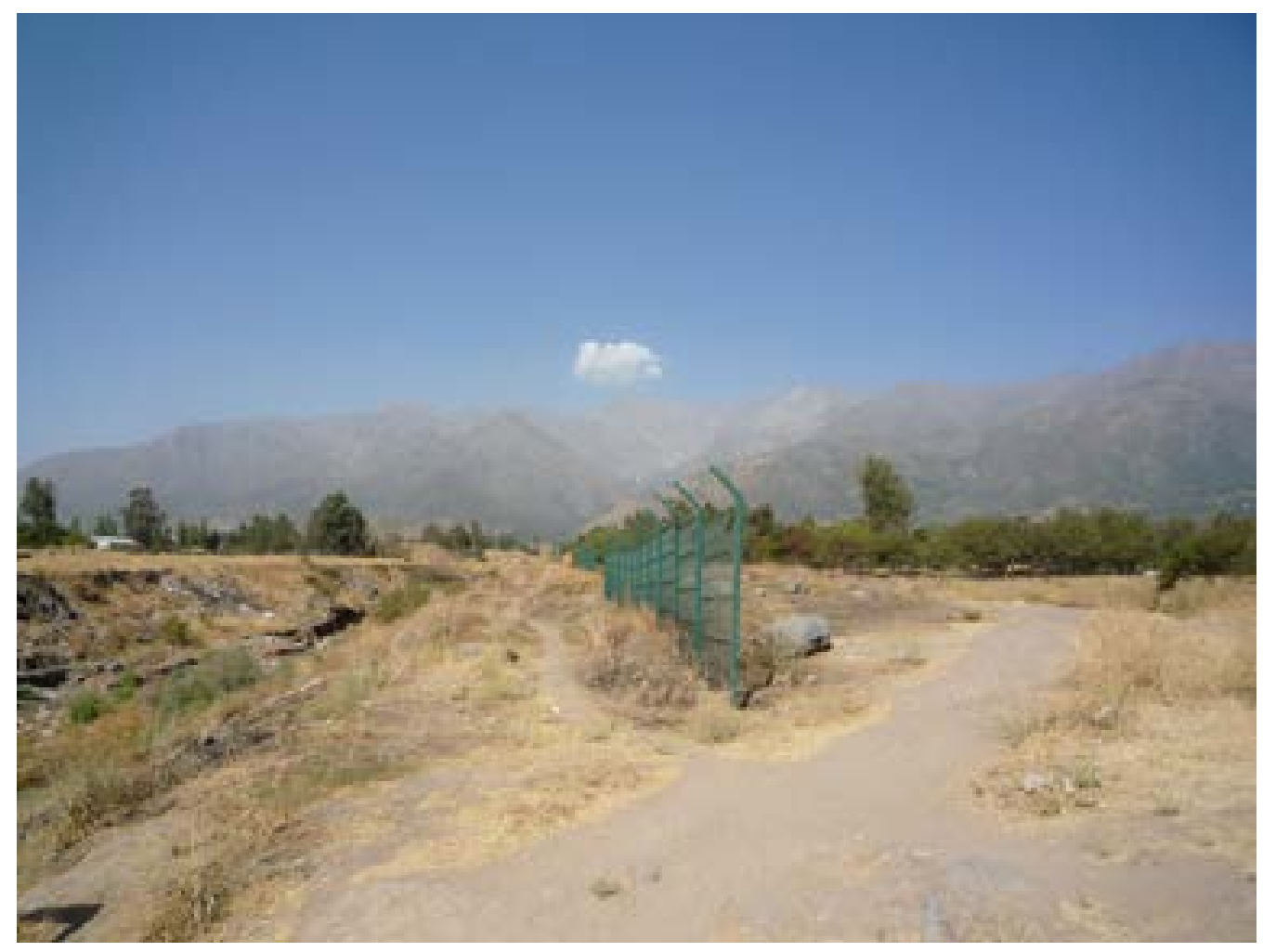

Fotografía de la autora.

\section{Del evento físico al proceso social.}

Las representaciones en cuanto al peligro son cambiantes. En ciertas circunstancias específicas, los estudios científicos que logran medir o mostrar los riesgos pueden llegar a tener reconocimiento político o público. Independientemente del uso que se haga de los estudios científicos (instrumental, declarativo, vinculante o no), el trabajo llevado a cabo por geógrafos en relación con la precordillera ha ido permeando cada vez más el debate público y político. Así, en 2014, un grupo de científicos de la Universidad de Chile, en su mayoría geógrafos, publican un estudio sobre "Determinación de amenazas y análisis de riesgo del sector precordillerano de la Comuna de La Florida" (Ferrando, 2014). Al respecto, el alcalde de la comuna de La Florida señala que este "estudio responde a un mandato moral que se tiene con los vecinos, tras el aluvión que ocurrió en 1993, en la quebrada de Macul" (La Segunda, 2014) (el énfasis es nuestro). A partir del trabajo de los científicos, el alcalde puede declarar que "este estudio es una señal clara, contundente y definitiva de que no se puede seguir construyendo más hacia la precordillera" (La Segunda, 2014), aun cuando diferentes proyectos inmobiliarios sigan en obras a los pies de la Cordillera de los Andes en diferentes comunas del país. 
Los peligros también pueden ser invisibilizados, por ejemplo, cuando vemos cómo se desarrollan proyectos inmobiliarios en la precordillera en las mismas comunas afectadas hace unos años por el aluvión.

Frente al peligro, no podemos sino hablar de experiencias, en plural. $O$, para retomar una expresión de John Dewey, experimentamos cosas pero no para crear una [sola] experiencia, ya que "constantemente hay experiencia, pues la interacción entre el ser vivo y su ambiente hace parte del proceso mismo de la existencia" (Dewey, 2010, p. 81).

A partir de lo que nos dice Dewey, podemos pensar que la experiencia del desastre post aluvión es una experiencia vivida diferentemente, que no está acabada, no es una experiencia sino más bien un proceso a partir del cual los entrevistados sienten, se expresan, toman partido, encuentran posiciones, se comprometen, se disputan, enfrentan contradicciones y conflictos.

Para los habitantes, el aluvión es un proceso en curso, en construcción, mientras que para las autoridades se trata más bien de un evento preciso, situado en el tiempo. Como lo propone Revet (2006, 2010), los eventos como los aluviones permiten observar cómo un fenómeno físico se transforma en un fenómeno social, por ende deben ser pensados "no como un dato sino que como un constructo, como un proceso" (Dewey, 2010, p. 43).

Las autoridades deben reaccionar en el momento, deben dar respuesta al evento social y físico, explicar las causas, definir acciones. Para los servicios públicos, el análisis se sitúa en el presente, en el momento en que se manifiesta el aluvión, no antes ni después.
En el informe citado más arriba, la Secretaría Regional Ministerial de Salud concluye que posteriormente al trabajo llevado a cabo con los funcionarios de diferentes servicios públicos con las víctimas del aluvión, se trata de una "experiencia muy positiva" en el sentido que "beneficia no sólo a la población afectada sino que también a las instituciones y a las personas participantes" (Secretaría Regional Ministerial de Salud, 1999, p. 38).

Para las autoridades, la evaluación es hecha sobre la respuesta que ellas pudieron dar en la situación de urgencia. Pero para los habitantes, el problema se inscribe en el largo plazo. Se sitúa en un contexto más largo pues para ellos el aluvión no es solo la urgencia del momento, no es sólo un evento, sino más bien un proceso, una experiencia que precede y que se prolonga más allá del 3 de mayo de 1993. Posteriormente al aluvión, los vecinos comienzan a organizarse, constituyen pruebas, designan responsables, explican las causas, difunden investigaciones científicas frente a públicos no expertos, transforman saberes expertos en saberes profanos, accesibles a diferentes públicos (Biskupovic \& Canteros, 2019).

A juzgar por las entrevistas con José, él y sus vecinos habían escuchado decir que mucho antes del aluvión de 1993, en 1937 "se abrió la quebrada" (entrevista del 17/04/2008). Las referencias a las condiciones "monstruosas" de la cordillera permiten a los habitantes expuestos a estos peligros que, como José, llegaron hace muchos años a vivir a este lugar, explicar que algunas veces las quebradas tienen comportamientos que no corresponden a sus estados normales. Algunas veces, la naturaleza actúa de manera ininteligible o inesperable para el hombre. Estas explicaciones de José van 
en el mismo sentido que lo que señalan los geógrafos: las quebradas "necesitan desahogar su furia", actuando sorpresivamente.

Las descripciones y explicaciones científicas van a servir a los habitantes para intentar probar la negligencia de las autoridades. Progresivamente, tal como vimos más arriba, los políticos van a referirse ocasionalmente a los estudios científicos también. Pero es interesante notar que, para los científicos, la naturaleza, las quebradas, son estables e inestables, tal como señala José, tienen comportamientos fuera de lo normal. Para Roberto, ex habitante de Lo Cañas y actualmente investigador de un instituto de física en París, "cuando el medio ambiente es estable, la geofísica no es importante" (entrevista, 04/11/2008). Pero, en el caso de Santiago, considerando que se trata además de un país sísmico, "la geofísica debiera estar en el centro de las políticas de desarrollo urbano", señala. Sin embargo, "la especulación inmobiliaria se hace como si no hubiera discurso científico", hay "muy poco intercambio con las autoridades, no les interesan los estudios científicos. Lo que nosotros hacemos no tiene incidencia" (entrevista Roberto, 04/11/2008). En el caso aquí estudiado, los informes científicos, posteriormente al aluvión de 1993, permean el discurso ciudadano y en ocasiones puntuales, como la que vimos, el político.

Ana, una de las grandes archivistas del aluvión ${ }^{13}$, señala que "todo el mundo está de acuerdo. Todos los científicos están de acuerdo que el piedemonte, que [en] el cerro, no se tiene que construir, no se tiene que tocar" (entrevista del 07/05/2008).

La descripción científica sirve de prueba a los ciudadanos comprometidos en la defensa y protección de la cordillera en Santiago, tanto frente a otros ciudadanos como con políticos. De cierta forma, los estudios científicos permiten a los ciudadanos comprometidos legitimar sus argumentos. De esta manera, los argumentos científicos se transforman en los principales fundamentos del compromiso ciudadano.

Los argumentos técnicos son soportes para los ciudadanos para discutir frente a las autoridades, para que desde el Estado se escuche la experticia. La intención de los vecinos es explicar "lo que sucede", reafirmando las especificidades de la precordillera e integrando el lugar de los seres humanos en el análisis del comportamiento de la naturaleza.

Mientras que, desde el Estado, la responsabilidad recae en la naturaleza, en lo imprevisible, tal como vimos antes, los vecinos comprometidos van a buscar volver inteligible y explícito el término de precordillera. No es lo natural en sí lo que ocasiona los desastres; se trata de constituir evidencias, de desnaturalizar la naturaleza, institucionalizándola. Es en la experticia científica que los vecinos van a encontrar las pruebas más sólidas para mostrar cómo funciona la naturaleza y distinguir la acción humana en los cambios que observan en sus barrios. Hacer frente al problema de la falta de consideración de las particularidades que caracterizan la precordillera implica para los habitantes desnaturalizar lo natural, es decir, mostrar que las acciones de la naturaleza son explicables, que los efectos de las acciones, aun las más aleatorias, pueden ser previsibles, que los efectos que puede ocasionar un desastre "natural" son de alguna manera controlables y que las muertes pueden evitarse. Se trata de cambiar la mirada de las autoridades frente a este espacio, constituir una experticia para explicar cómo funciona 
la precordillera, en base a pruebas. Aun cuando esto no les permite una consideración automática de las autoridades y desarrolladores inmobiliarios para resguardar el piedemonte, al menos puede legitimar una denuncia. El objetivo es desnaturalizar el medio ambiente donde viven e institucionalizar la protección de este.

Los habitantes progresivamente van constituyendo pruebas en base a "desclasificaciones", es decir, volviendo públicos artículos científicos y legales, principalmente. Estas pruebas les permiten hacer visibles los peligros, no a partir de un miedo explícito, sino que más bien a partir de una gestión del peligro. Esta gestión implica hacer públicos informes, reglamentos y estudios para "controlar" el peligro, nombrándolo, explicándolo, clasificándolo e integrándolo a la vida cotidiana.

Así, el peligro vivido y el peligro potencial son, más que un miedo, un dato, un antecedente para los vecinos para demostrar la importancia de proteger un sitio. Contrariamente a lo que señalan los informes producidos en el Estado antes señalados, en que la naturaleza y su "impredictibilidad" provocan catástrofes tal y como los aluviones, los habitantes parten del principio que los peligros no son producidos únicamente por la voluntad de la naturaleza (Douglas, 1966) sino que también por actividades humanas. Sin embargo, en el caso de José, por ser uno de los habitantes entrevistados que está más expuesto al peligro y que vivió el aluvión, él integra esta dimensión monstruosa para justificar que vive en esta inestabilidad natural.

En este sentido, la comprensión de la naturaleza se vuelve objeto de investigación para los habitantes (Dewey, 2010) para entender y defender sus particularidades. Considerando que a pesar del aluvión de 1993 el Municipio ha seguido aprobando permisos de construcción en la precordillera, los habitantes están en alerta frente al devenir del territorio, se transforman en los guardianes, constantemente en alerta tanto frente a eventos climáticos como a intervenciones humanas. En este marco nace la organización colectiva en torno a la defensa de la precordillera (Biskupovic, 2015) en las que las preocupaciones están situadas y arraigadas en el territorio.

El conocimiento construido y reformulado por los ciudadanos a partir de los datos científicos y de la desclasificación de documentos (Biskupovic \& Canteros, 2019) les permite afirmar que hoy en día, frente a nuevos proyectos potenciales "las cosas serían diferentes" pues "tienen la información", como señala José en la entrevista anteriormente citada.

\section{Conclusiones}

En este artículo en un primer momento retrasamos históricamente los procesos y decisiones que vuelven posible el aluvión de 1993. Luego analizamos cómo los diferentes actores comprometidos en el desastre perciben y describen el aluvión. Estos antecedentes son importantes para comprender el proceso político, de compromiso, que desarrollan progresivamente los habitantes de la precordillera. Este pasado reciente permite entender como las personas explican los desastres "naturales", y cómo estos no se deben solamente a razones "naturales" sino que la "falta es compartida", como vimos anteriormente.

En el año 1994, el Ministerio de Obras Públicas construye piscinas de contención para evitar futuros aluviones, pero estas no han sido 
suficientes. Eventos como el del año 1993 se han repetido el 2004 y 2005 afectando a los nuevos habitantes de los condominios recién construidos en Santa Sofía de Lo Cañas. En entrevistas con habitantes de este sector, constatamos que, al ser viviendas menos vulnerables, los afectados no sufrieron pérdidas completas ni hubo muertos. Sin embargo, las inundaciones destruyeron casas y avenidas.

Los habitantes afectados por el aluvión de 1993 fueron desplazados de la zona, encontrándose hoy en condiciones más desfavorables que antes del aluvión, según los entrevistados. Ya sea porque fueron instalados en viviendas sociales más pequeñas, o porque en estas también se instalaron habitantes de otros sectores de la capital, aumentando la vulnerabilidad y marginalidad social en el barrio, o bien porque ya no pudieron ejercer los trabajos y oficios que realizaban antes en sus parcelas (talleres, pequeña agricultura, carpintería), los antiguos habitantes cercanos a la quebrada no se sienten conformes. Por otra parte, quienes se quedaron ilegalmente en las zonas peligrosas cercanas a la quebrada, no pueden optar a financiamientos ni prestamos por estar en sectores de exclusión urbana.

La precordillera está gobernada por una cierta indeterminación y, frente a una situación como el desastre post aluvión, las configuraciones en el territorio cambian. Los habitantes, por su parte, ponen en cuestión las medidas adoptadas por las autoridades, tal como las piscinas de contención, por ser insuficientes. Los expertos recopilan datos para explicar la catástrofe y sugerir medidas. Las autoridades reaccionan frente a los hechos e intentan transformar la naturaleza responsable del desastre.
El aluvión aparece como un peligro inevitable en este caso, el que será puesto en duda por los habitantes y expertos.

Los vecinos están constantemente evaluando la posibilidad que ocurran nuevos eventos catastróficos (Revet, 2006) y solicitando evaluaciones a los expertos. Esta expertisación de los habitantes va a influir en la organización de una defensa de la precordillera anclada en el territorio.

A partir de este artículo, podemos señalar que la noción de peligro no proviene del azar, si no que este es explicable, medible, probable. La vulnerabilidad frente a los riesgos es la consecuencia de decisiones tomadas por personas (habitantes, autoridades, planificadores, expertos, etc.). El riesgo es el resultado de decisiones (conscientes o inconscientes) de una multiplicidad de actores (Revet, 2006). Tal como señala Ana en la entrevista, "el municipio tenía un montón de argumentos técnicos para decir que no, que nosotros no queremos que se llene el cerro con esa cantidad de casas porque es muy peligroso, habiendo pasado el aluvión (...)." Sin embargo, estos procesos territoriales están sujetos a múltiples conocimientos que de alguna manera compiten o se excluyen. "El aluvión del 93', los científicos lo habían previsto años antes, ya había un estudio que decía que era muy peligroso", agrega Ana en la misma entrevista (7/05/2008), "que podía pasar esto o lo otro, nadie los infló, nunca jamás (...) Y después nadie los infló tampoco, cuando hicieron el Plan Regulador Metropolitano, e hicieron la expansión urbana hasta la punta del cerro más o menos, nadie le preguntó nada a ningún arquitecto, a ningún ingeniero, a ningún geólogo, a ni un geógrafo a ni un climatólogo, nada de nada." (entrevista Ana, 7/05/2008). 
En este sentido, más allá de las respuestas técnicas e institucionales frente a la urgencia del desastre, es importante poner atención en cómo los habitantes, a partir de la experiencia del aluvión, van a transformar la situación en una oportunidad política para hacer valer ciertas definiciones, caracterizaciones y particulari- dades respecto al lugar donde viven, al mismo tiempo que le otorgan legitimidad a la palabra y al rol de los científicos. En este marco, el saber desplegado y "acumulado" por los habitantes, a través de los años y de la experiencia podría alimentar la gestión de la precordillera, junto al saber científico y técnico.

\section{Notas}

${ }^{1}$ L. es arquitecto, trabaja en la oficina de planificación de la municipalidad de La Florida desde 1988.

${ }^{2}$ Este artículo se basa en un terreno etnográfico y en entrevistas realizadas entre el 2008 y en el 2011 en el marco de mi tesis doctoral en Santiago, fundamentalmente en la comuna de La Florida (Biskupovic, 2015).

${ }^{3}$ Oficina Nacional de Emergencia, www.sigweb.cl [consultado en agosto 2014].

4 Para más detalle sobre la organización de defensa de la precordillera, ver mis trabajos anteriores (Biskupovic, 2009, 2011, 2015).

${ }^{5}$ En agosto del 2014, gracias a la ley de transparencia solicité en diversas instituciones públicas información sobre la legalización, división y construcción de las poblaciones cercanas a la Quebrada de Macul (El Progreso, Domínguez, El Esfuerzo). Recibí una respuesta a fines de septiembre con los permisos de construcción de estas poblaciones. Sin embargo, estos documentos eran difícilmente analizables pues, con un lenguaje legal y burocrático, se limitaban a las regulaciones de las construcciones de las viviendas sociales $\sin$ referencias al territorio ni a los habitantes. En 1984 la Municipalidad de La Florida aprueba la construcción de El Progreso y en 1987 la del Esfuerzo.

${ }^{6}$ Tanto en la Biblioteca Nacional como en la Municipalidad de La Florida, prácticamente ningún documento contenía un análisis histórico que pudiese permitir saber por qué las viviendas sociales fueron construidas a algunos pasos de las quebradas. Solo encontramos artículos técnicos sobre el comportamiento de las quebradas del Servicio Nacional de Geología y Minería (SERNAGEOMIN). Sólo una entrevista fue aceptada con los miembros de la oficina de Desarrollo Urbano del MINVU. Este encuentro, sin embargo, no fue muy exitoso, el funcionario que debía recibirme ese día no llegó y otros funcionarios del servicio, que no estaban al tanto de la cita acordada previamente, llegaron a recibirme no de muy buena gana. Ellos respondieron a mis preguntas sin mucho entusiasmo mostrándome que estaba interfiriendo en su trabajo.

${ }^{7}$ Los nombres de las personas han sido cambiados. A José lo conocí el 2008, es uno de los habitantes "antiguos" del sector, vivió el aluvión y vio como este se llevaba su casa. Posteriormente, recolectó mucha información y se transformó en un interlocutor recurrente. José me llevó a conocer y entrevistar otros habitantes antiguos como él. Durante esta etnografía, regularmente me lo encontraba en diferentes actividades de la municipalidad y del colectivo creado en 2006. Todavía vive a algunos metros de la Quebrada de Macul, en el barrio El Esfuerzo.

${ }^{8}$ Ver el trabajo del historiador Mario Garcés sobre el movimiento de los habitantes de las poblaciones (2002). Para una historia de las tomas y las poblaciones de Santiago, ver los capítulos 6 y $7 \mathrm{del}$ sociólogo Vicente Espinoza (1988b, p. 239-328).

${ }^{9}$ Arquitecta de unos sesenta años que vive en un barrio de parcelas, bastante más acomodado que el de José.

${ }^{10}$ Término negativo que emerge en los años 1960 en Chile para nombrar las casas construidas precariamente de los barrios pobres (villas miserias). Remite a la idea de callampas no sólo por sus formas, sino que también debido a que crecen y se multiplican fácilmente.

${ }^{11}$ Radio Universidad de Chile sobre la precordillera del 12/06/2008.

${ }^{12}$ En trabajos anteriores exploro con más detalle las acciones del colectivo creado en el 2006 para proteger la precordillera (Biskupovic, 2011).

${ }^{13}$ Recopiló un gran número de artículos de prensa e informes científicos después del aluvión de 1993. Gracias al acceso que me dio a sus archivos, pude releer gran parte de los documentos publicados en la prensa post desastre. 


\section{Bibliografía}

Arnold, M. (2003). Autoproduccion de la amenaza ambiental en la sociedad contemporanea. Revista MAD, 9, 1-31.

Arnold, M. \& Urquiza, A. (2010). Las amenazas ambientales: Una visión desde la teoría de los sistemas sociopoiéticos". In E. Aliste \& A. Urquiza, Medio Ambiente y Sociedad: Conceptos, metodologías y experiencias desde las ciencias humanas y sociales (RIL, pp. 27-53). Santiago: RIL editores.

Biskupovic, C (2015). Forger la participation. Une ethnographie de la culture civique experte à Santiago: Le cas du Réseau de Défense de la précordillère (Tesis de doctorado). Ecole des Hautes Etudes en Sciences Sociales, París, Francia.

Biskupovic, C. \& Canteros, E. (2019). Movilizando saberes ciudadanos: Encontrar un lugar, construir la verdad. Revista Austral de Ciencias Sociales, (36), 7-28. https://doi.org/10.4206/rev.austral. cienc.soc.2019.n36-01

Blok, A. \& Jensen, T. E. (2011). Bruno Latour: Hybrid Thoughts in a Hybrid World. London: Routledge.

Blondiaux, L. \& Traïni, C. (2018). La Démocratie des émotions. París: Presses de Sciences Po.

Bonelli, C. 2017. Aguas Equivocas en el Sur de Chile. In: Bonelli C., and Vila G. (eds).

A contra-corriente: agua y conflicto en Latinomamerica. Quito: Editorial AbyaYala, 119-136.

Callon, M. (2004). The role of hybrid communities and sociotechnical arrangements in the participatory design. Journal of the Center for Information Studies, 5(3), 3-10.

Callon, M., Lascoumes, P. \& Barthe, Y. (2001). Agir dans un monde incertain. Essai sur la démocratie technique. París: Seuil.

Céfaï, D. (1996). La construction des problèmes publics. Définitions de situations dans des arènes publiques. Réseaux, 14(75), 43-66.

Céfaï, D., Terzi, C. \& Collectif. (2012). L'expérience des problèmes publics. París: Editions de l'Ecole Pratiques de Hautes Etudes en Sciences Sociales.

Charvolin, F. (1997). L'invention du domaine de l'environnement. Au tournant de l'année 1970 en France. Strates. Matériaux pour la recherche en sciences sociales, 9, 1-16.

Corvalan, N., Kovacic, I. \& Muñoz, O. (1997). Quebrada de Macul: El aluvión del 3 de mayo 1993. Causas y consecuencias. Revista Geográfica de Chile: Terra Australis, 42, 139-167.

Descola, P. \& Tola, F. (2018) ¿Qué es la naturaleza? Buenos Aires: Editorial Teseo.

Dewey, J. (2010). Le public et ses problèmes. París: Gallimard.

Di Méo, G. (1998). Géographie sociale et territoires. Paris: Nathan.

Dockendorff, E., Rodriguez, A. \& Winchester, L. (2000). Santiago de Chile: Metropolization, globalization and inequity. Environment and Urbanization, 12(1), 171-183. https://doi. org/10.1177/095624780001200112

Douglas, M. (1966). Purity and danger: An analysis of the concepts of pollution an taboo. London New York: Routledge.
El Mercurio. (5 de julio de 1993a). Se construirán 2 mil casas para los damnificados.

(5 de septiembre de 1993b). Aluvión.

(5 de septiembre de 1993c). El derrumbe del cielo.

(24 de agosto del 2009). Las "lecciones" dejadas por los 16 peores desastres en Chile.

Espinoza, V. (1988). Para una historia de los pobres de la ciudad (Ediciones SUR). Santiago: Ediciones SUR

Estenssoro, F. (2007). Antecedentes sobre la protección al medio ambiente en el pensamiento de libre mercado en Chile (década de los noventa del s. XX). Estudios Avanzados, 5(8), 35-59.

Ferrando, F. (2014). Determinación de amenazas y análisis de riesgo del sector precordillerano de la Comuna de La Florida (No. Municipalidad de la Florida).

Garay, I. (1989). Inundaciones y anegamientos en la Comuna de La Florida. Santiago, Chile: Cordillera, Centro de Estudios Municipales.

Garcés, M. (2002). Tomando su sitio: El movimiento de pobladores de Santiago, 1957-1970. Santiago: Lom Ediciones.

Gramaglia, C. (2006). La mise en cause environnementale comme principe d'association. Casuistique des affaires de pollution de rivières: L'exemple des actions contentieuses de l'Association nationale de protection des eaux et rivières (ANPER-TOS). (Ecole des Mines de Paris).

Ingold, T. (2000). The Perception of the Environment: Essays on Livelihood, Dwelling and Skill. London: Routledge.

Ingold, T. \& Palsson, G. (2013). Biosocial Becomings: Integrating Social and Biological Anthropology. Cambridge y New York: Cambridge University Press.

Jirón, P. (2009). Prácticas de Movilidad Cotidiana Urbana: Un Análisis para Revelar Desigualdades en la Ciudad. En Tironi, M. \& Perez, F., SCL Espacios, Prácticas y Cultura Urbana. Santiago: ARQ Ediciones, 176-189.

La Nación. (1993, 7 de abril). Goteras en campamento de emergencia.

La Segunda. (2014, 14 de marzo). Estudio U. de Chile: Habitantes de la precordillera de La Florida están en riesgo por aluviones o terremotos.

Latour, B. (2005). Reassembling the social: An introduction to actor-network-theory. Oxford; New York: Oxford University Press.

(2012). Esperando a Gaia. Componer el mundo común mediante las artes y la política. Cuadernos de Otra parte. Revista de letras $y$ artes, 26, 67-76.

Lolive, J. (2006). Des forums hybrides à l'esthétisation des espaces publics en France. Cahiers de Géographie Du Québec, 50(140), 151-171.

Lorenz, T. (2014). Chilean architects gain global recognition. Financial Times. Retrieved from http://www.ft.com/intl/cms/ s/2/278c0770-e68b-11e3-9a20-00144feabdc0.html\#axzz34AxMMBSC

Martínez, B. (2009). Susceptibilidad de remoción en masa en la 
Quebrada de Macul, Región Metropolitana. Facultad de Ciencias Físicas y Matemáticas, Universidad de Chile.

Ministerio Secretaría General de la Presidencia (1994). Ley sobre Bases Generales del Medio Ambiente 19300. Biblioteca del Congreso Nacional de Chile.

Muñoz, O. (1990). Quebrada de Macul: Un factor de desequilibrio físico en la comuna de la Florida. Revista Geográfica de Chile Terra Australis, 32, 103-134.

Naranjo, J. A. \& Varela, J. (1996). Flujos de detritos y barro que afectaron el sector oriente de Santiago el 3 de mayo de 1993. Boletín Del Servicio Nacional de Geología y Minería, 47, 42.

ONEMI. (1996). Antecedentes preliminares estudio comparativo efecto sobre las personas eventos de origen antrópico/eventos de origen natural, períodos 1985-1996 [Informe]. Retrieved July 17, 2014, from http://190.196.69.246/web/handle/123456789/161

Oxhorn, P. (1992). Review "Puente Alto. Desafíos de la transición en la comuna", by Marcelo Solervicens. Canadian Journal of Latin American and Caribbean Studies / Revue Canadienne Des Études Latino-Américaines et Caraïbes, 17(33), 147-150.

Padilla, C. (2006). Análisis de factores meteorológicos desencadenantes de remociones en masa en el sector oriente de Santiago (Memoria para optar al Título de Geólogo). Departamento de Geología, Universidad de Chile.
Pino, A., \& Ojeda, L. (2013). Ciudad y hábitat informal: Las tomas de terreno y la autoconstrucción en las quebradas de Valparaíso. Revista INVI, 28(78), 109-140. https://doi.org/10.4067/S071883582013000200004

Revet, S. (2006). Le risque négocié. Conflits et ajustements autour de la reconstruction de Vargas (Venezuela). Autrepart, 37(1), 163-181. https://doi.org/10.3917/autr.037.0163 (2010). Le sens du désastre. Terrain, (54), 42-55. https:// doi.org/10.4000/terrain.13936

Robles, F. (2000). El desaliento inesperado de la modernidad (1. ed.). Santiago de Chile: Red Internacional del Libro. (2005). Contramodernidad y globalizaciones paradojicas: La configuracion de las sociedades perifericas de riesgo. Esbozos para reubicar lo politico. Revista MAD, 12, 1-26.

Revel, J. (2011). Micro verus macro: Escalas de observación y discontinuidad en la historia. Tiempo Histórico, 2, 15-26.

Secretaría Regional Ministerial de Salud. (1999). Principales desastres: Región Metropolitana 1990-1999.

Urry, J. (2015) Climate Change and Society. En Michie, J. \& Cooper, C.L. (eds). Why the Social Sciences Matter. Palgrave Macmillan, London, 45-59.

Veyne, P. (1996). Comment on écrit l'histoire. París: Seuil. 